\title{
VALJANOST, POUZDANOST I OSJETLJIVOST TESTA UDARAC NOGOM - MAE GERI
}

\author{
Žarko Kostovski ${ }^{1}$, Marko Zeljković ${ }^{2}$, Lulzim Ibri ${ }^{3}$, Elena Soklevska ${ }^{4}$ i Boško Zaborski ${ }^{4}$ \\ ${ }^{1}$ Fakultet fizičke kulture, Univerzitet "Sv. Kiril i Metodije" Skoplje, Makedonija \\ ${ }^{2}$ Fakultet fizičkog vaspitanja i sporta, Univerzitet Banja Luka, Bosna i Hercegovina \\ ${ }^{3}$ Sektor sporta, Opština Prizren, Srbija \\ ${ }^{4}$ Karate club "Mak Petrol”,Skopje, Macedonia
}

\section{SAŽETAK}

Specifične motoričke sposobnosti u modernom sportu vjerovatno su odlujučujući fakotor u rejšavanju sportskih zadataka i postizanju sportskog uspjeha. Udarci rukom i nogom u karate sportu su dominantne tehnike koje pomažu karatisti da osvaja poene ili pobjedi u borbi. Karate sport, a posebno sportsku diciplinu borba (kumite), karakterišu polustrukturalna kretanja, a kao najvažnije motorne sposobnosti ističu se eksplozivnost, brzina i koordinacija. Predmet ovog istraživanja proističe iz prethodnih znanja i argumenata, a usmjeren je ka određivanju mjernih karakteristika (pouzdanosti, osjetljivosti i valjanosti) specifičnog motoričkog testa "Mae Geri".

Istraživanje je rađeno u Republici Makedoniji na uzorku od 30 ispitanika (karatista), muškaraca, starijih od 18 godina. Tokom istraživanja na uzorku ispitanika primjenjena je jedna manifestna specifičnomotorička varijabla (novokostruisani složeni test), karakteristična za karate sport. Cilj ovog istraživanja bio je da se utvrde mjerne karakteristike novokonstruisanog testa. Korišćenjem Hotteling metode utvrđena je faktorska valjanost ovog testa kao i njegove latentne dimenzije, a uspostavljena je i glavna komponenta u skladu sa Kaiser-Gutman kriterijom. Na osnovu dobijenih rezultata istraživanja došlo se do zaključaka koji se odnose na mjerne karakteristike primjenjenog testa, a prije svega na faktor valjanost, osjetljivost i pouzdanost istog.

Ključne riječi: karate, Mae-Geri, mjerne karakteristike.

\section{UVOD}

Karate sport, a posebno sportska disciplina borba (kumite), odlikuje se polistrukturalnim pokretima, a kao najznačajnije motoričke sposobnosti izdvajaju se eksplozivnost, brzina i koordinacija. Specifične motoričke sposobnosti u savremenom sportu su možda presudan faktor u rješavanju sportskih zadataka i postizanju sportskog uspeha. Udarci rukom i nogom u karate sportu su dominantne tehnike koje pomažu sportisti da skuplja poene ili pobjedi u borbi. Polustrukturalni pokreti koji karakterišu karate borbu (kumite) uveliko definišu strukturu pokreta i najvažnije motorne karakteristike koje stoje iza toga: agilnost, brzina i eksplozivnost. Dosadašnja istraživanja savremenih tehničkih i taktičkih pokazatelja karate borbe pokazuju da najveći uticaj imaju različite tehnike (Koropanovski, Dopsaj i Jovanović, 2008).

Neka saznanja o nivou razvoja motoričkih sposobnosti mogu se dobiti procjenom različitih ispoljavanja koje registrujemo odgovarajućim motoričkim testovima, tzv. mjernim instrumentima. Pošto se motorika čovjeka mjeri indirektno, cjelokupna procedura mjerenja mora da bude standardizovana, a testovi motorike (mjerni instrumenti) treba da karakteriše zadovoljavajuće mjerne osobine kao što su: validnost, pouzdanost, osjetljivost, tačnost i slično. U tom slučaju dobijeni rezultati neke motoričke sposobnosti na jednom uzorku ispitanika mogu se uporediti sa rezultatima koji utvrđenim na drugom uzorku ispitanika pod istim uslovima (Kostovski i Georgiev, 2009a).

Ozbiljan razvoj karatea kao sporta zahtijeva 
savremeni pristup, koncepte, obrazce, aktivnosti i postupke u treningu novijim karate tehnologijama, posebno u vezi sa strukturom antroploških karakteristika i njihove korelacije i specifičnog uticaja na sportske vještine. Pored toga, neophodno je da se uspostavi dijagnoza i validnost instrumenata koji se koriste za modeliranje, dijagnostiku, planiranje, programiranje i praćenje efekata operacionalizacije trenažnog procesa (Doder, Malacko, Stanković i Doder, 2011).

Polazeći od te činjenice, mogu se uraditi određena istraživanja koje se odnose na utvrdivanje testova za procijenu nekih specifičnih motoričkih karakteristika u karate sportu (Костовски, 2005; Kostovski i Georgiev, 2009b; Kostovski, Mašić i Đukanović, 2011).

Neki mjerni instrumenti koji su se pokazali kao "dobri" za jednu populaciju ili uzorak, ne znači da će biti "dobri" za drugu populaciju ili uzorak. To je posebno slučaj kod ispitanika različitog uzrasta, različitog pola i drugih različitih obilježja. Uskladu sa problemom ovog istraživanja postoji potreba za stalnom provjerom mjernih karakteristika testova. S tim u vezi Костовски (2004) je proveo istraživanje da se utvrde mijerne karakteristike nekih stnadardnih i specifičnih motoričkih testova u karateu u različitim hronološkim uzrastima.

Obzirom na činjenicu da se ljudske motorne reakcije mogu ostvariti samo uz procjenu motoričkih sposobnosti $\mathrm{u}$ raličitim ispoljavanjima, one se mogu zabilježiti kroz različite motoričke procedure - mjernim instrumentima (Kostovski i Georgiev, 2009c).

$\mathrm{U}$ prethodnom periodu istraživaći su koristili postojeće testove za procjenu motoričkih sposobnosti karatista (Koletić, 1992; Kuleš i Muratagić, 1993). Međutim, ti testovi nisu se pokazali u potpunosti specifični da zadovolje potrebe današnjeg karate sporta.

Navedeni zaklučci ukazuju na potrebu za provođenjem novih istraživanja u cilju konstruisanja i stvaranja novih testova i provjere njihovih metrijskih karakteristika (Kostovski i Georgiev, 2009c).

Pošto su primjena dijagnostičkih morfoloških osobina i osnovnih motoričkih vještina u procesu treninga karatista povezani sa interdisciplinarnim pristupom, gdje je složenost kretnih struktura i antropoloških interdisciplinarnih karakteristika ličnosti visoka, potrebno je uključiti što je moguće više osnovnih, specifičnih i situacionih mjernih instrumenata. Kod konstrukcije instrumenata mora se imati na umu informacija o valjanosti za svaki mjerni instrument, što znači da primjeneni instrumenti moraju imati zadovoljavajuće mjerne karakteristike kao što su validnost, objektivnost, pouzdanost, diskriminantnost (Doder i saradnici, 2011)

U cilju da se omoguće bolja kineziološka istraživanja, u novije vrijeme koriste se mjerni instrumenti za registrovanje i mjerenje ispoljavanja specifičnih motoričkih sposobnosti (Sertić, Vidranski i Segedi, 2010), a proces treninga sportista u velikoj mjeri je planiran, programiran i nadgledan.

Ali, da bi jedan test bio validan i primjenljiv mora takođe da bude pouzdan. Znanja o specifičnim zahtijevima u karateu mogu pomoći trenerima, pa čak i sportistima, da optimizuju programa treninga (Chaabène i saradnici, 2012).

$\mathrm{Na}$ osnvu svega prethodno rečenog ovo istraživanje je sprovedeno sa glavnim ciljem da identifikuje, analizira i uporedi mjerne karateristike specifične motorne varijable Mae Geri kod vrhunskih karatista.

\section{METODE}

\section{Uzorak ispitanika}

Tokom ovog istraživanja, obuhvaćeno je 30 karatista, potencijalnih i standardnih reprezentativaca Makedonije, starijih od 18 godina, profilisanih kao karatisti seniori. Istraživanje je sprovedeno na odabranom uzorku ispitanika muškog pola.

\section{Uzorak varijabli}

Na uzorku ispitanika, u ovom istraživanju je primenjena jedna manifestna specifično motorička varijabla za procenu specifične karate frekvencije boljom nogom.

1. Udarac u vreću MAE GERI boljom nogom za 10 s (MAEG),

\section{Opis testa}

Test se izvodi u sportskoj sali, odnosno u sali u kojoj karatisti treniraju. Za sprovođenje testa je potrebna bokserka vreća, zakačena na zidu i štoperica, kojom merač meri vreme. Ispitanik staje pred vreću u karakterističnom borbenom stavu "fudo daci", na odstojanju koje on sam određuje, na osnovu dužine svoje noge. Zadatak ispitanika je da pravilno izvede što je moguće veći broj udaraca "mae geri” boljom nogom, za vrijeme od deset sekundi. Mjerač stoji bočno od ispitanika, uključuje štopericu kada ispitanik počne sa izvođenjem testa i broji pravilno izvedene udarce za vreme od 10 sekundi. Test se ponavlja četiri puta, sa pauzom između svakog ponavljanja.

\section{Metode obrade podataka}

Dobijeni rezultati mjerenja manifestnog specifičnomotoričkog testa su obrađeni odgovarajućim statističkim metodima, koji su bile u funkciji postavljenog cilja i 


\section{TABELA 1}

Osnovni statistički parametri testa Udarac nogom u vré́u - Mae Geri.

\begin{tabular}{lrrrcrrr}
\hline & $n$ & $M$ & Min & Max & $S D$ & Skew. & Kurt. \\
\hline MAEG1 & 30 & 10,87 & 6 & 16 & 2,58 & 0,22 & $-0,80$ \\
\hline MAEG2 & 30 & 9,43 & 5 & 16 & 2,53 & 0,68 & 0,44 \\
\hline MAEG3 & 30 & 9,47 & 5 & 15 & 2,40 & 0,38 & $-0,24$ \\
\hline MAEG4 & 30 & 10,03 & 5 & 15 & 2,27 & 0,09 & $-0,97$ \\
\hline
\end{tabular}

Legenda: $\mathbf{n}$ - Broj ispitanika; M - Aritmetička sredina; Min - Minumum; Max - Maksimun;

SD - Standardna devijacija; Skew -Skjunis; Kurt - Kurtozis; MAEG - Udarac nogom

u vreću - Mae Geri; 1-4 - Prvo, drugo, treće i četvrto ponavljanja testa.

\section{TABELA 2}

Matrica interkorelacije ajtema na testu Udarac nogom u vré́u - Mae Geri.

\begin{tabular}{l|rrrr}
\hline & MAEG1 & MAEG2 & MAEG3 & MAEG4 \\
\hline MAEG1 & 1,00 & & & \\
\hline MAEG2 & 0,93 & 1,00 & & \\
\hline MAEG3 & 0,94 & 0,94 & 1,00 & \\
\hline MAEG4 & 0,95 & 0,87 & 0,89 & 1,00 \\
\hline
\end{tabular}

Legenda: MAEG - Udarac nogom u vreću - Mae Geri; 1-4 - Prvo, drugo, treće i četvrto ponavljanja testa.

\section{TABELA 3}

Hotelingov postupak.

\begin{tabular}{lcc}
\hline & $H$ & $T^{2}$ \\
\hline MAEG1 & 0,985 & $\mathbf{0 , 8 6}$ \\
\hline MAEG2 & 0,965 & $\mathbf{0 , 8 6}$ \\
\hline MAEG3 & 0,971 & $\mathbf{0 , 9 0}$ \\
\hline MAEG4 & 0,956 & $\mathbf{0 , 8 6}$ \\
\hline
\end{tabular}

zadataka istraživanja. Tokom obrade rezultata mjerenja specifično-motoričkog testa, t.j. za svaku kompozitno ponavljanje, izračunate su sljedeće osnovne mjere centralne tendencije i dispercije: aritmetička sredina $(M)$, standardna devijacija (SD), minimalni (Min) i maksimalni (Max) rezultat. Prema simetričnosti distribucije rezultata, procijenjeno je da li test predstavlja lak ili težak motorni zadatak ispitanika (Skew.), a prema zaobljenosti distribucije rezultata, utvrđena je homogenost rezultata u testu (Kurt.). Osjetljivost kao mjerna karakteristika je utvrđena prema odnosu između aritmetičke sredine i standardne devijacije. Za utvrđivanje povezanosti između ajtema, izračunat je Pirsonov koeficijent korelacije $(r)$. Faktorska validnost varijable utvrđena je Hotelingovim postupkom, kojom se utvrđuju latentne dimenzije varijable, gde je značajna glavna komponenta utvrđena prema Kaiser-Gutmanovom
TABELA 4

Koeficijent relijabilnosti.

\begin{tabular}{lr}
\hline$\dot{\alpha}$ & 0,977 \\
$r_{n}$ & 0,978 \\
$I C C$ & 0,923 \\
\hline$\lambda$ & 3,757 \\
$\%$ & 93,915 \\
\hline
\end{tabular}

kriterijumu, pri čemu se dobijaju: projekcije ajtema prve glavne komponente $(H)$, vrijednosti izolovanih karakterističnih korjena $(\lambda)$ i doprinos izolovanih karakterističnih korijena u objašnjenju ukupnog varijabiliteta varijanse, izraženog u postotcima (\%). Interna validnost ajtema je utvrđena prema projekcijama ajtema prve glavne komponente, t.j. izolovanog karakterističnog korena $(H)$. Zajednički predmet mjerenja je utvrđen ako je izolovan jedan karakterisitčni korjen. Homogenost ajtema je utvrđena prema vrijednosti karakterističnog korjena $(\lambda)$. Za utvrđivanje relijabilnosti izračunato je više koeficijenata $\mathrm{i}$ indeksa relijabilnosti, među kojima se nalaze: Krombahov indeks varijabilnosti, izračunat prema projekcijama ajtema uz prvu glavnu komponentu (Cronbach- $-\dot{\alpha}$ ), Spirman-Braunov koeficijent pouzdanosti $\left(r_{n}\right)$-izračunat na osnovu prosečnih korelacija između kompozitnih 
merenja, kao i koeficijent interne korelacije za svaki test posebno (ICC).

\section{REZULTATI I DISKUSIJA}

Analizom vrednosti aritmetičkih sredina četiri izmerenih ajtema može da se primeti sledeće: u prvom i četvrtom ajtemu su postignuti najviši rezultati u odnosu na ostala dva ajtema, gde postoji blago opadanje broja ponavljanja u jedinici vremena. Četiri izračunate vrednosti prikazuju stanje stabilnosti u odnosu na izvođenje testa. Pozitivna promena (minimalna), koja se pojavljuje u oba ajtema, daje rezultat kod motivisanosti samih sportista, da kod izvođenja prvog i četvrtog pokušaja daju svoj maksimum. Relativno dobra diskriminativnost testa koji je poseduje nam predočuje vrednosti varijabiliteta, odnosno standardnih devijacija.

Prema nagibu distribucije rezultata u ajtemama, moguća je konstatacija da ovaj test predstavlja relativno lak zadatak za tretirani uzorak ispitanika (aritmetičke sredine četiri ajtema u zoni srednjih rezultata). Za četiri ajteme u ovom testu utvrđena je normalna distribucija rezultata. Vrijednosti koeficijenata korelacija između ajtema su vrlo visoke, pozitivne i statistički značajne sa vrednostima od 0,87 do 0,95 .

Kod ove varijable utvrđeno je da četiri ajteme imaju jedan zajednički predmet mjerenja i relativno visoku homogenost, na šta nas upućuje vrijednost izolovanog karakterističnog korjena prve glavne komponente $\lambda$ $=3,757$ i objašnjava $93,915 \%$ ukupnog varijabiliteta varijanse. Koeficijenti relijabilnosti (Cronbach $\alpha=$ $0,977$ i Spearman-Brown $=0,978)$ imaju vrlo visoke i zadovoljavajuće vrednosti, kao i internu korelaciju koja iznosi 0,923 . U odnosu na ono što je do sada izneseno za varijablu "Mae geri", može se reći sledeće: Test se odlikuje visokim stepenom osetljivosti i zadovoljavajućim koeficijentima varijabilnosti. Takođe, test je jednostavan za primenu i lak za objašnjenje.

Prema Bukviću (1982) svaki koeficijent varijabilnosti vrednosti veće od 0,80 ukazuje na visoku varijabilnost testova, a vrednosti veće od 0,90 ukazuju na vrlo visoku varijabilnost.

\section{ZAKLJUČAK}

Izvršeno je istraživanje odabranog uzorka od 30 ispitanika (karatista), uzrasta starijih od 18 godina (karatisti seniori), muškog pola, u Makedoniji. Na primerku ispitanika je primenjena jedna manifestna specifično-motorna varijabla (novokonstruisani kompozitni test), karakteristična za karate sport.

Dobijeni rezultati iz ovog istraživanja ukazuju na zaključke koji se odnose na mjerne karakteristike primenjene varijable, a prije svega na njenu faktorsku validnost, osetljivost i relijabilnost.

Test "Mae geri" se odlikuje faktorskom validnošću, visokim stepenom osetljivosti i zadovoljavajućim koeficijentima varijabilnosti, što znači da je eventualna pogreška u merenju veoma mala.

Koeficijenti varijabilnosti (Cronbach $\alpha=0,977 \mathrm{i}$ Spearman-Brown $=0,978)$ su sa vrlo visokim $\mathrm{i}$ zadovoljavajućim vrijednostima, kao i interna korelacija koja iznosi 0,923. Takođe, test je jednostavan za primjenu i lak za objašnjenje.

Test procjenjuje motoričku dimenziju, definisanu kao specifična karate frekvencija donjih ekstremiteta.

$\mathrm{Na}$ osnovu dobijenih rezultata, test se preporučuje u trenažnoj tehnologiji i selekciji karatista u bateriji testova za procjenu specifične karate frekvencije donjih ekstremiteta (do konstruisanja novog testa).

\section{LITERATURA}

Bukvić, A. (1982). Načela iẓade psiboloških testova [Principals of psychological tests]. Beograd, RS: Zavod za udžbenike i nastavna sredstva.

Chaabène, H., Hachana, Z., Attia, A., Mkaouer, B., Chaabouni, S, \& Chamari, K. (2012). Relative and absolute reliability of karate specific aerobic test (ksat) in experienced male athletes. Biolo. Sport, 29(3), 211-215. doi: 10.5604/20831862. 1003485

Doder, D., Malacko, J., Stanković, V., \& Doder, R. (2011). Predictor validity of morphological and basic motor variables for assessment and monitoring of the karate punch with the lead arm (oi-tsuki). Biolo. Sport, 28(4), 265-270. doi: 10.5604/965485

Koletić, Z. (1992). Metrijske karakteristike situaciono motorickih testova u karate [Metric characteristics of situational motor tests in karate]. Unpublished thesis, University of Zagreb, Fakultet za fizičku kulturu.

Koropanovski, N., Dopsaj, M., \& Jovanović, S. (2008). Characteristics of Pointing Actions of Top Male Competitors in Karate at World and European level. Brazilian Journal of Biomotoric, 2(4), 241-251.

Костовски, Ж. (2004) Мерни карактеристики на моторните и спечифично моторииките тестови кај карате спортисти од разлинна хронолошка возрасm [Measuring features of motor and specific motor tests in karate athletes from different chronological age]. Unpoublished doctorial dissertation, University "Ss. Cyril and Methodius" of Skopje, Faculty of Physical Culture. 
Костовски Ж. (2005) У тврдуванје на мерните карактеристики на одредени специфично моторни тестови за проценунување на специфична карате-координација, кај каратеспортистки пом^ади кадетки [Determining the measurement characteristics of certain specific motor tests for assessment of specific karate coordination in younger female karate athletes-cadets]. Физичка култура, 2, 115-118.

Kostovski, Ž., \& Georgiev, G. (2009a). Relijabilnost primenjenih testova za procenu specifične karate koordinacije kod vrhunskih karatista sa različite hronološke uzrasti, [Test reliability for assessment the appropriateness of specific coordination in elite karate athletes with different chronological ages]. In B. Mikić (Ed.), II Medunarodni simpozijum Sport $i$ qdravlje (pp. 127-130). Tuzla, BA: Fakultet za tjelesni odgoj i sport.

Kostovski, Ž., \& Georgiev, G. (2009b). Validnost testova za procenu specifične karate koordinacije kod 12 i 14 godišnjih karatista [Test validity tests for the assessment of specific coordination karate at 12 and 14 years old karate athletes]. In B. Mikić (Ed.), II Medunarodni simpozijum Sport $i$ zdravlje (pp. 120-126). Tuzla, BA: Fakultet za tjelesni odgoj i sport.
Kostovski, Ž., \& Georgiev, G. (2009c). Measure characteristics of motor tests for assessing rhythmic structure and explosive strength with karate athletes and non-athletes at the age of 12 . Sport scientific and practical aspect, 6(2), 37-42.

Kostovski, Ž, Mashik, Z, \& Gukanovik, N. (2011). Measuring performance of the strokes with leg (mavashi geri and ushiro geri) in karate sport. In. A. Biberović (Ed.), IV Medunarodni simpozijum Sport $i$ zdravlje (pp. 245-248). Tuzla, BA: Fakultet za tjelesni odgoj i sport..

Kuleš, B., \& Muratagić, Dž. (1993). Konstrukcija i validacija situacijsko-motoričkih testova za karatiste [Construction and validation of situational-motor tests for karate athletes]. Kineziologija, 25(1-2), 52-57.

Sertić, H., Vidranski, T., \& Segedi, I. (2010). Terenski testovi za procjenu specifičnih motoričkih sposobnosti karatista [Field tests for the assessment of specific motor skills karate athletes]. In I. Jukić, C. Gregov, S. Šalaj, L. Milanović, and T. Trost-Bobić (Eds.), VIII godišnja medunarodna konferencija Kondicijska priprema sportaša (pp. 223-226). Zagreb, HR: Kineziološki fakultet Sveučilišta u Zagre; Udruga kondicijskih trenera Hrvatske.

Primljeno: 13. oktobra 2012 Izmjene primljene: 5. decembra 2012

Odobreno: 30. decembra 2012

Korespondencija: Dr Žarko Kostovski Fakultet fizičke kulture Železnička bb 1000 Skoplje Makedonija

Telefon: 0038970340797

Faks: 0038923119755

E-mail: zarkokostovski@hotmail.com 